\title{
Interleukin-34: Regulator of T Lymphocytes in Rheumatoid Arthritis
}

\author{
Jea-Hyun Baek* \\ Research and Development, Biogen Inc, US \\ *Corresponding author: Jea-Hyun Baek, Biogen Inc., 225 Binney St, Cambridge, MA 02142, US
}

\section{ARTICLE INFO}

Received: 慧 August 05, 2019

Published: 慧 August 12, 2019

Citation: Jea-Hyun Baek. Interleukin-34: Regulator of $\mathrm{T}$ Lymphocytes in Rheumatoid Arthritis. Biomed J Sci \& Tech Res 20(3)-2019. BJSTR. MS.ID.003458.

\begin{abstract}
Interleukin-34 (IL-34) is a pleiotropic cytokine, which is implicated in various autoimmune diseases. Interestingly, clinical studies have found that IL-34 is markedly upregulated in the serum and synovium of patients with rheumatoid arthritis (RA), giving rise to a growing interest in understanding the role of IL-34 in RA. Although several studies demonstrated that IL-34 levels closely correlate with the disease severity, the function of circulating and synovial IL-34 in RA is still largely elusive. IL-34 was originally identified as a ligand of the colony-stimulating factor-1 receptor (CSF-1R), which is crucial for the survival, proliferation, and differentiation of mononuclear phagocytes (e.g. monocytes, macrophages $[\mathrm{M} \phi]$ and dendritic cells [DC]). Of note, these IL-34-responsive cells are antigen-presenting cells, which bridge innate and adaptive immunity (e.g. through priming and instructing T lymphocytes). Thus, synovial IL-34 expression has been associated with the regulation of synovial $\mathrm{M} \phi$ and linked to pathologic T-cell activation in RA. In this review, we discuss the current state of knowledge on the role of IL-34 in RA and, especially, focus on the impact of IL-34 on T lymphocyte activation in RA based on findings from translational and clinical studies.
\end{abstract}

Abbreviations: CSF-1: Colony-Stimulating Factor-1; CSF-1R: CSF-1 Receptor; DC: Dendritic Cell(s); HLA: Human Leukocyte Antigen; IFN: Interferon; $\mathrm{M} \phi$ : Macrophage(s); LITAF: lipopolysaccharide-Induced TNF factor LPS: lipopolysaccharide; PBMC: Peripheral Blood Mononuclear Cell(s); PTP- : Receptor-Type Tyrosine-Protein Phosphatase Zeta; RA: Rheumatoid Arthritis; Teff: Effector T Lymphocyte(s); TNF- $\alpha$ : Tumor Necrosis Factor Alpha; Treg: Regulatory T Lymphocyte(s)

\section{Introduction}

Rheumatoid Arthritis (RA) is a common inflammatory autoimmune disease with complex etiologies, which primarily affects joints. RA is primarily caused by self-reactive immune responses and involves a variety of immune cells, including (1) innate immune cells (e.g. macrophages ( $\mathrm{M} \phi)$ and neutrophils), which are the first responders in inflammation; and (2) adaptive immune cells (e.g. B and $\mathrm{T}$ lymphocytes), which trigger highly effective secondary immune responses targeting specific antigens. $\mathrm{M} \phi$, neutrophils, and effector T lymphocytes (Teff) are prominent immune cells in the synovium of RA patients [1]. Interestingly, several alleles of human leukocyte antigen (HLA) class II histocompatibility antigen, DRB1 beta chain (encoded by HLADRB1) have been highly associated with increased incidence of RA and higher inflammatory activity in early RA [2-5], indicating that the interaction between antigen-presenting cells and $\mathrm{T}$ lymphocytes followed by an aberrant T-cell activation is a key mechanism in the pathogenesis of RA.

Recently, the monocyte/M $\phi /$ dendritic cell (DC) cytokine IL34 has been suggested as a biomarker and therapeutic target in RA [6-8], supported by clinical studies demonstrating that IL-34 is robustly elevated in the serum, synovial fluid, and tissue in patients with RA [8-15]. However, while increasing evidence indicates that IL-34 plays an important role in the pathogenesis of RA, the precise mechanism underlying the increased levels of circulating and synovial IL-34 in RA [6], as well as the exact role of IL-34 in the pathophysiology of RA remains elusive. Although several functions 
of IL-34 have been described, the immunological role of IL-34 is still under debate, as IL-34 can be both pro- and anti-inflammatory depending on the clinical setting [16-21]. Notably, several studies have proposed a role of IL-34 in the regulation of T lymphocytes in RA. In this review, we discuss the current state of knowledge of the role of IL-34 in RA and, especially, focus on the impact of IL-34 on T-cell regulation in RA.

\section{IL-34 In RA}

IL-34 is a ligand for the colony-stimulating factor-1 receptor (CSF-1R), which is essential for the maintenance of mononuclear phagocytes, including monocytes, $\mathrm{M} \phi$, DC in tissue homeostasis and inflammation $[22,23]$. Studies have identified fibroblast-like synoviocytes (FLS) as a source for IL-34. IL-34 was found to be produced by FLS upon stimulation with tumor necrosis factoralpha (TNF- $\alpha$ ) in vitro [10]. CSF-1R has another ligand, which is colony-stimulating factor-1 (CSF-1; also known as M-CSF). Although IL-34 and CSF-1 bind to the same receptor and display overlapping functions [24,25], both ligands show no structural similarities [26]. CSF-1R is expressed on cells of mononuclear phagocyte lineage (e.g. monocytes, $\mathrm{M} \phi$, DC) and myeloid precursors. Besides, CSF-1R is also detected in other cells (FLS [15] and osteoclasts [27-29]), which are also implicated in RA, indicating that the role of IL-34/ CSF-1R axis may not be restricted only to the immune system. Recent studies identified two more receptors of IL-34, which are receptor-type tyrosine-protein phosphatase zeta (PTP- $\zeta$ ) [30] and syndecan-1 [31].

However, our knowledge of IL-34 functions mediated by these receptors is limited. So far we only know that: (1) PTP- $\zeta$ activation by IL-34 induces phosphorylation of focal adhesion kinase (FAK) and paxillin in glioblastoma cells, which in turn restrains signaling pathways associated with proliferation, clonogenicity and motility [30]; (2) IL-34-mediated syndecan-1 activation modulates CSF1R signaling pathways, but enhancing the migratory capacity of myeloid cells [31]. Collectively, increasing evidence indicates that IL-34-mediated activation of PTP- $\zeta$ and syndecan- 1 has a negative effect on CSF-1R signaling. It is possible that IL-34 directly acts on T and B lymphocytes via PTP- $\zeta$ (and syndecan-1), as PTP- $\zeta$ protein was detected in $\mathrm{T}$ and $\mathrm{B}$ lymphocytes in renal biopsies from mice with advanced lupus nephritis [32]. Interestingly, $\mathrm{M} \phi$ were also positive for PTP- $\zeta$ in this study [32], although transcriptional
PTP- $\zeta$ expression is not evident in in vitro generated bone marrowderived $\mathrm{M} \phi$ before and after stimulation (Supplemental Figure 1 in [16]). The immunological functions of IL-34-induced PTP- $\zeta$ and syndecan- 1 are so far unclear and deserve future investigations.

Nevertheless, the effects of IL-34/CSF-1R axis on M $\phi$ are unambiguous as CSF-1R signaling has been well-studied for its impact on $\mathrm{M} \phi$ biology [33] and is known to be important for $\mathrm{M} \phi$ expansion in arthritic tissue. In RA, M $\phi$ number positively correlates with the disease severity [34-36]. Along these lines, local IL-34 injection during collagen-induced murine arthritis was associated with RA pathology [37]. IL-34-dependent mechanisms, which may support RA pathogenesis, are suggested as follows: (1) expanding $\mathrm{M} \phi[16,22,23]$ (2) inducing T-helper cell (Th17) response via activation of monocytes/M $\phi$ or FLS in vivo [10,15,37]; (3) activating inflammatory pathways in FLS [15]; and (4) promoting osteoclast formation [10]. However, as mentioned in the previous section, IL34 has double-edged roles in immunity [16-21]. Accordingly, recent studies documented a dual role for IL-34: (1) polarizing $\mathrm{M} \phi$ towards an immunosuppressive phenotype in different disease models [38]; and (2) expanding IL-34-stimulated $\mathrm{M} \phi$ and potentiating regulatory T (Treg) cells suppressing Teff cells [17,39].

\section{The Impact of IL-34 on T Lymphocytes}

The initial events in the pathogenesis of RA comprise two steps: (1) activation of the antigen-presenting cells including DC, M $\phi$ and activated B cells; and (2) the subsequent priming of T lymphocytes with arthritis-associated antigens [40]. Th17 cells and IL-17 are closely associated with the pathogenesis of RA [41]. Shortly, after it became evident that IL-34 expression is elevated in the blood and synovium of RA patients, Tian et al. reported that the presence of recombinant IL-34 induces the upregulation of IL-17 in peripheral blood mononuclear cells (PBMC) isolated from patients with RA [11]. This was the first study, which suggested a link between IL-34 and Th17 cells (Table 1). Similarly, the link between IL-34 and IL17 expression is also found in other inflammatory diseases, such as Sjögren's syndrome, where IL-34 is suggested to regulate monocytes and/or M $\phi$, which are involved in the pathogenesis [18]. Over the last three years, several studies have focused on identifying the molecular mechanisms that underlie the link between IL-34 and IL17 and found that IL-34 stimulates FLS $[15,42]$ and/or monocytes $[42,43]$ to express IL-17 (Table 1). 
Table 1: The impact of IL-34 on T-cell regulation (chronological order).

\begin{tabular}{|c|c|c|c|}
\hline Affected T cell & IL-34-stimulated cell & Effects & Ref. \\
\hline Th17 & Human PBMC from patients with RA & $\begin{array}{l}\text { Upregulation of IL-17 protein (ELISA) after stimulation with } \\
\text { recombinant IL-34 }\end{array}$ & [11] \\
\hline Th17 & Human RA FLS & $\begin{array}{l}\text { Upregulation of IL- } 6 \text { expression in RA FLS leading to the in- } \\
\text { creased numbers of Th17 cells in an RA FLS-CD4 } 4^{+} \text {T co-culture } \\
\text { system }\end{array}$ & [15] \\
\hline Th17 & $\begin{array}{l}\text { Systemic administration (Peritoneal } \\
\text { injection) }\end{array}$ & $\begin{array}{l}\text { Upregulation of IL-17 expression in the synovium of mice with } \\
\text { collagen-induced arthritis }\end{array}$ & [37] \\
\hline Th17 & Human monocyte cell line THP-1 & $\begin{array}{l}\text { Upregulation of IL-6 (plus IL-23, IL-21, IL-1b) expression in THP- } \\
1 \text { leading to the increased numbers of Th17 cells in a THP-1-CD4+ } \\
\qquad \text { T co-culture system }\end{array}$ & [43] \\
\hline Th1+17 & $\begin{array}{c}\text { Chicken M } \phi \text { cell line HD11 and fibro- } \\
\text { blast cell line OU2 }\end{array}$ & Upregulation of Th1 (IFN- $\gamma$ ) and Th2 (IL-17, IL-12p40) & {$[42]$} \\
\hline
\end{tabular}

Wang et al. demonstrated that (1) IL-34 acts on human FLS in an autocrine manner by activating the JNK/P38/NF- $\kappa$ B pathway leading to the upregulation of IL- 6 and IL-34 increases the number of Th17 cells in an RA FLS-CD4+ T co-culture system [15]. Similarly, the same group showed that ex vivo CD4+ Tlymphocytes co-cultured with IL-34-stimulated monocytic cell line THP-1 give rise to more Th17 T cells as compared to those co-cultured with unstimulated cells [43]. However, it is to note that IL-34 alone cannot activate pro-inflammatory signaling pathways in monocytes, as shown by numerous studies $[16,24,25,33]$, suggesting that different pathways may be involved in FLS versus monocytes leading to the same T-cell response. In line with clinical studies, systemically administered IL34 was found to aggravate the severity of arthritis and upregulate IL-17 expression in the collagen-induced arthritis model in mice, indicating that circulating IL-34 can instruct synovial cells to produce IL-17 [37].

However, Garcia et al. inconsistently reported that exogenous addition or blockage of IL-34 has no effect on the production of inflammatory mediators in the synovium of mice with collageninduced arthritis [34]. Most recently, Truong et al. studied the role of IL-34 in the chicken system and showed that IL-34 is a pro-inflammatory cytokine in this system inducing a variety of inflammatory mediators including all types of interferons (IFN; $\alpha$, $\beta, \gamma$ ), pro-inflammatory interleukins (IL-1 $\beta,-12 \mathrm{p} 40$ and -17) and lipopolysaccharide (LPS)-induced TNF factor (LITAF) in both chicken fibroblast and monocyte cell lines [42]. However, no similar study in humans or mice reported that IL-34 has such effects on monocytes; the observations in the chicken system might be system-specific. Future studies need to address how circulating IL34 is produced and whether circulating IL-34 has other additional effects in RA (more discussion in the next section).

\section{Novel Roles of IL-34 In T-Cell Regulation}

Recent studies suggest a novel role of IL-34 in immunosuppression [38]. Bézie et al. demonstrated that IL-34-activated $\mathrm{M} \phi$ expand and potentiate Treg cells suppressing Teff cells in transplant recipients [17]. Treg cells, a population of CD25+CD4+ cells expressing the transcription factor FOXP3 can effectively suppress T-cell activation in RA [44]. Indeed, disturbed Treg/Th17 balance [45] or Treg deficiency [46] is prominent in patients with RA. Of note, (spleen) CD8+ regulatory $\mathrm{T}$ lymphocytes and human FoxP3+ $\mathrm{T}$ lymphocytes were found to express IL-34, suggesting a paracrine loop between $\mathrm{M} \phi$ and regulatory T lymphocytes [17]. Interesting- 
ly, IL-34-expanded Treg cells display a stronger immunosuppressive activity compared to non-IL-34-expanded Treg cells [17]. As IL-34 is prominent in RA patients, there is a growing interest to target IL-34 in RA $[6,7,24,47,48]$. To develop a successful therapeutic approach based on IL-34, we need to more precisely understand the function of IL-34 in RA. Future studies need to address whether IL-34-expanded RA-specific Treg cells can be used in the therapy for RA.

\section{Conclusion}

It is clear that the severity of RA positively correlates with the number of synovial $\mathrm{M} \phi . \mathrm{M} \phi$ play an important role in RA pathogenesis. The increase in the number of sublining $\mathrm{M} \phi$ in the synovium is an early hallmark of active RA, and high numbers of $\mathrm{M} \phi$ are a prominent feature of inflammatory lesions [49]. Indeed, $\mathrm{M} \phi$ have been implicated in driving pathology in a variety of inflammatory diseases [50,51]. Of note, the RA synovium expresses both key M $\phi$ survival factors, IL-34 and CSF-1: While CSF-1 is expressed in the synovial sublining, IL-34 is detected in the sublining and additionally in the intimal lining layer [34]. Therefore, there is a consensus that IL-34 and CSF-1 need to be targeted simultaneously to remove pathologic M $\phi$ in the RA synovium [34,47]. Interestingly, recent studies by Guillonneau and colleagues shed light on the novel immunoregulatory role of IL-34 $[17,39]$. They demonstrated that IL-34 expands $\mathrm{M} \phi$ and potentiate Treg cells. Indeed, Treg cells are be of therapeutic use [52,53], and it would be interesting for the future to study whether IL-34 administration along with partial $\mathrm{M} \phi$ depletion provides an effective combination therapy facilitating a sustained improvement of patients living with RA.

\section{Funding Statement}

These studies are funded by Biogen, Inc.

\section{Disclosures}

JHB is an employee of Biogen, Inc.

\section{References}

1. Weyand CM (2000) New insights into the pathogenesis of rheumatoid arthritis. Rheumatology 39: 3-8.

2. Seidl, C, Koch U, Buhleier T, Frank R, Möller B, et al. (1997) HLA-DRB1*04 subtypes are associated with increased inflammatory activity in early rheumatoid arthritis. Br J Rheumatol 36(9): 941-944.

3. Gregersen PK, J Silver, RJ Winchester (1987) The shared epitope hypothesis. An approach to understanding the molecular genetics of susceptibility to rheumatoid arthritis. Arthritis Rheum 30(11): 12051213.

4. Weyand, CM, Hicok KC, Conn DL, Goronzy JJ (1992) The influence of HLA-DRB1 genes on disease severity in rheumatoid arthritis. Ann Intern Med 117(10): 801-806.

5. Plenge RM (2009) Rheumatoid arthritis genetics: 2009 update. Curr Rheumatol Rep 11(5): 351-356.

6. Udomsinprasert WJ, Jittikoon, S Honsawek (2019) Interleukin-34 as a promising clinical biomarker and therapeutic target for inflammatory arthritis. Cytokine Growth Factor Rev 47: 43-53.
7. Zhou RP, Wu XS, Xie YY, Dai BB, Hu W, et al. (2016) Functions of interleukin-34 and its emerging association with rheumatoid arthritis. Immunology 149(4): 362-373.

8. Zhang F, Rui Ding, Ping Li, Cuili Ma, Ding Song, et al. (2015) Interleukin-34 in rheumatoid arthritis: potential role in clinical therapy. Int J Clin Exp Med 8(5): 7809-7815.

9. Chemel M, Le Goff B, Brion R, Cozic C, Berreur M, et al. (2012) Interleukin 34 expression is associated with synovitis severity in rheumatoid arthritis patients. Ann Rheum Dis 71(1): 150-154.

10. Hwang SJ (2012) Interleukin-34 produced by human fibroblast-like synovial cells in rheumatoid arthritis supports osteoclastogenesis. Arthritis Res Ther 14(1): R14.

11. Tian Y, Choi B, Kang SS, Chang JH, Kim YG, et al. (2013) Elevated serum and synovial fluid levels of interleukin-34 in rheumatoid arthritis: possible association with disease progression via interleukin-17 production. J Interferon Cytokine Res 33(7): 398-401.

12. Moon SJ, Hong YS, Ju JH, Kwok SK, Park SH, et al. (2013) Increased levels of interleukin 34 in serum and synovial fluid are associated with rheumatoid factor and anticyclic citrullinated peptide antibody titers in patients with rheumatoid arthritis. J Rheumatol 40(11): 1842-1849.

13. Chang SH, Choi BY, Choi J, Yoo JJ, Ha YJ, et al. (2015) Baseline serum interleukin-34 levels independently predict radiographic progression in patients with rheumatoid arthritis. Rheumatol Int 35(1): 71-79.

14. Yang S, Jiang S, Wang Y, Tu S, Wang Z, et al. (2016) Interleukin 34 Upregulation Contributes to the Increment of MicroRNA 21 Expression through STAT3 Activation Associated with Disease Activity in Rheumatoid Arthritis. J Rheumatol 43(7): 1312-1319.

15. Wang B, Ma Z, Wang M, Sun X, Tang Y, et al. (2017) IL-34 Upregulated Th17 Production through Increased IL-6 Expression by Rheumatoid Fibroblast-Like Synoviocytes. Mediators Inflamm 2017: 1567120.

16. Baek JH, Zeng R, Weinmann-Menke J, Valerius MT, Wada Y, et al. (2015) IL-34 mediates acute kidney injury and worsens subsequent chronic kidney disease. J Clin Invest 125(8): 3198-3214.

17. Bezie S, Picarda E, Ossart J, Tesson L, Usal C, et al. (2015) IL-34 is a Treg-specific cytokine and mediates transplant tolerance. J Clin Invest 125(10): 3952-3964.

18. Ciccia F, Alessandro R, Rodolico V, Guggino G, Raimondo S, et al. (2013) IL-34 is overexpressed in the inflamed salivary glands of patients with Sjogren's syndrome and is associated with the local expansion of proinflammatory CD14(bright)CD16+ monocytes. Rheumatology (Oxford) 52(6): 1009-1017.

19. Esaki H, Ewald DA, Ungar B, Rozenblit M, Zheng X, et al. (2015) Identification of novel immune and barrier genes in atopic dermatitis by means of laser capture microdissection. J Allergy Clin Immunol 135(1): 153-163.

20. Lin X, Luo H, Yan X, Song Z, Gao X, et al. (2018) Interleukin-34 Ameliorates Survival and Bacterial Clearance in Polymicrobial Sepsis. Crit Care Med 46(6): e584-e590.

21. Franze E, Monteleone I, Cupi ML, Mancia P, Caprioli F, et al. (2015) Interleukin-34 sustains inflammatory pathways in the gut. Clin Sci (Lond) 129(3): 271-280.

22. Greter M, Lelios I, Pelczar P, Hoeffel G, Price J, et al. (2012) Stromaderived interleukin-34 controls the development and maintenance of langerhans cells and the maintenance of microglia. Immunity 37(6): 1050-1060.

23. Wang Y, Szretter KJ, Vermi W, Gilfillan S, Rossini C, et al. (2012) IL-34 is a tissue-restricted ligand of CSF1R required for the development of Langerhans cells and microglia. Nat Immunol 13(8): 753-760.

24. Wei S, Nandi S, Chitu V, Yeung YG, Yu W, et al. (2010) Functional overlap but differential expression of CSF-1 and IL-34 in their CSF-1 receptormediated regulation of myeloid cells. J Leukoc Biol 88(3): 495-505. 
25. Boulakirba S, Pfeifer A, Mhaidly R, Obba S, Goulard M, et al. (2018) IL-34 and CSF-1 display an equivalent macrophage differentiation ability but a different polarization potential. Sci Rep 8(1): 256.

26. Ma X, Lin WY, Chen Y, Stawicki S, Mukhyala K, et al. (2012) Structural basis for the dual recognition of helical cytokines IL-34 and CSF-1 by CSF-1R. Structure 20(4): 676-687.

27. Yoshida H (1990) The murine mutation osteopetrosis is in the coding region of the macrophage colony stimulating factor gene. Nature 345(6274): 442-444.

28. Wiktor Jedrzejczak W, Bartocci A, Ferrante AW, Ahmed Ansari A, Sell KW, et al. (1990) Total absence of colony-stimulating factor 1 in the macrophage-deficient osteopetrotic (op/op) mouse. Proc Natl Acad Sci U S A 87(12): 4828-4832.

29. Cecchini MG, Hofstetter W, Halasy J, Wetterwald A, Felix R, et al. (1997) Role of CSF-1 in bone and bone marrow development. Mol Reprod Dev 46(1): 75-83.

30. Nandi S, Cioce M, Yeung YG, Nieves E, Tesfa L, et al. (2013) Receptortype protein-tyrosine phosphatase zeta is a functional receptor for interleukin-34. J Biol Chem 288(30): 21972-21986.

31. Segaliny AI, Brion R, Mortier E, Maillasson M, Cherel M, et al. (2015) Syndecan-1 regulates the biological activities of interleukin-34. Biochim Biophys Acta 1853(5): 1010-1021

32. Wada Y, Gonzalez-Sanchez HM, Weinmann Menke J, Iwata Y, Ajay AK, et al. (2019) IL-34-Dependent Intrarenal and Systemic Mechanisms Promote Lupus Nephritis in MRL-Fas(lpr) Mice. J Am Soc Nephrol 30(2): 244-259.

33. Baek JH (2019) The Impact of Versatile Macrophage Functions on Acute Kidney Injury and Its Outcomes. Front Physiol 10: 1016.

34. Garcia S, Hartkamp LM, Malvar Fernandez B, van Es IE, Lin H, et al. (2016) Colony-stimulating factor (CSF) 1 receptor blockade reduces inflammation in human and murine models of rheumatoid arthritis. Arthritis Res Ther 18: 75.

35. Ohno H, Uemura Y, Murooka H, Takanashi H, Tokieda T, et al. (2008) The orally-active and selective c-Fms tyrosine kinase inhibitor Ki20227 inhibits disease progression in a collagen-induced arthritis mouse model. Eur J Immunol 38(1): 283-291.

36. Paniagua RT, Anna Chang, Melissa M Mariano, Emily A Stein, Qian Wang et al. (2010) c-Fms-mediated differentiation and priming of monocyte lineage cells play a central role in autoimmune arthritis. Arthritis Res Ther 12(1): R32.

37. Zhang L, Cui M, Ding L, Xia L, Lu J, et al. (2018) Interleukin-34 Aggravates the Severity of Arthritis in Collagen-Induced Arthritis Mice by Inducing Interleukin-17 Production. J Interferon Cytokine Res 38(5): 221-225.

38. Foucher ED, Blanchard S, Preisser L, Garo E, Ifrah N, et al. (2013) IL-34 induces the differentiation of human monocytes into immunosuppressive macrophages. antagonistic effects of GM-CSF and IFNgamma. PLoS One 8(2): 56045 .

ISSN: 2574-1241

DOI: 10.26717/BJSTR.2019.20.003458

Jea-Hyun Baek. Biomed J Sci \& Tech Res

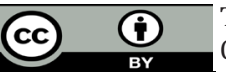

This work is licensed under Creative

Commons Attribution 4.0 License

Submission Link: https://biomedres.us/submit-manuscript.php
39. Bezie S, Meistermann D, Boucault L, Kilens S, Zoppi J, et al. (2017) Ex Vivo Expanded Human Non-Cytotoxic CD8 ${ }^{(+)}$CD45RC (low/-) Tregs Efficiently Delay Skin Graft Rejection and GVHD in Humanized Mice. Front Immunol 8: 2014.

40. Choy E (2012) Understanding the dynamics: pathways involved in the pathogenesis of rheumatoid arthritis. Rheumatology 51(5): 3-11.

41. Shen H, JC Goodall, JS Hill Gaston (2009) Frequency and phenotype of peripheral blood Th17 cells in ankylosing spondylitis and rheumatoid arthritis. Arthritis Rheum 60(6): 1647-1656.

42. Truong AD, Hong Y, Lee J, Lee K, Kil DY, et al. (2018) Interleukin-34 Regulates Th1 and Th17 Cytokine Production by Activating Multiple Signaling Pathways through CSF-1R in Chicken Cell Lines. Int J Mol Sci 19(6): 1665.

43. Wang B, Tang Y, Sun X, Ouyang X, Li H, et al. (2018) Increased IL-6 expression on THP-1 by IL-34 stimulation up-regulated rheumatoid arthritis Th17 cells. Clin Rheumatol 37(1): 127-137.

44. Smolen JS, Aletaha D, Koeller M, Weisman MH, Emery P, et al. (2007) New therapies for treatment of rheumatoid arthritis. Lancet 370(9602): 1861-1874.

45. Niu Q, Cai B, Huang ZC, Shi YY, Wang LL, et al. (2012) Disturbed Th17/ Treg balance in patients with rheumatoid arthritis. Rheumatol Int 32(9): 2731-2736.

46. Ehrenstein MR, Evans JG, Singh A, Moore S, Warnes G, et al. (2004) Compromised function of regulatory $T$ cells in rheumatoid arthritis and reversal by anti-TNFalpha therapy. J Exp Med 200(3): 277-285.

47. Masteller EL, BR Wong (2014) Targeting IL-34 in chronic inflammation. Drug Discov Today 19(8): 1212-1216.

48. Xu WD, Huang AF, Fu L, Liu XY, Su LC, et al. (2019) Targeting IL-34 in inflammatory autoimmune diseases. J Cell Physiol.

49. Udalova IA, A Mantovani, M Feldmann (2016) Macrophage heterogeneity in the context of rheumatoid arthritis. Nat Rev Rheumatol 12(8): 472 485.

50. Baek JH, Gomez IG, Wada Y, Roach A, Mahad D, et al. (2018) Deletion of the Mitochondrial Complex-IV Cofactor Heme A: Farnesyltransferase Causes Focal Segmental Glomerulosclerosis and Interferon Response. Am J Pathol 188(12): 2745-2762.

51. Baek JH, Many GM, Evesson FJ, Kelley VR (2017) Dysferlinopathy Promotes an Intramuscle Expansion of Macrophages with a CytoDestructive Phenotype. Am J Pathol 187(6): 1245-1257.

52. Shevach EM (2004) Regulatory/suppressor T cells in health and disease. Arthritis Rheum 50(9): 2721-2724.

53. Tang Q JA Bluestone (2006) Regulatory T-cell physiology and application to treat autoimmunity. Immunol Rev 212: 217-237.

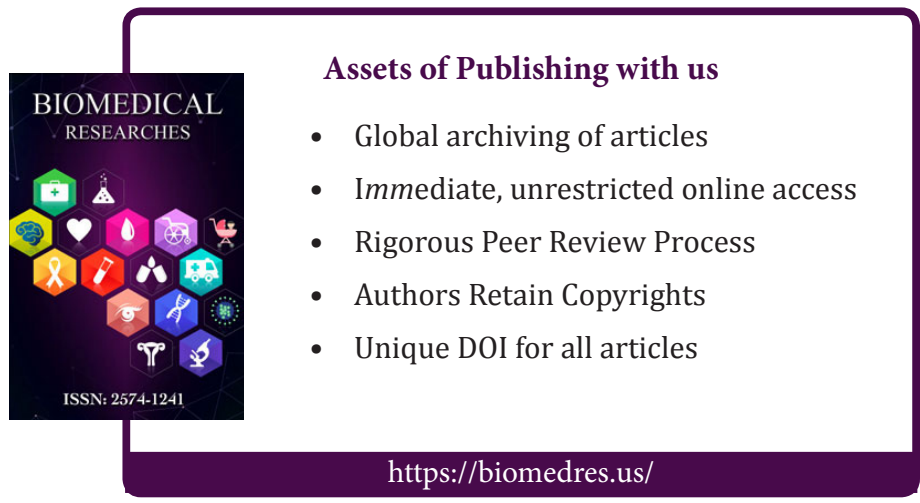

Copyright@ Jea-Hyun Baek| Biomed J Sci \& Tech Res| BJSTR. MS.ID.003458. 